\title{
PROJETO PRIMEIROS PASSOS: UMA ALTERNATIVA DE ACOLHIMENTO AOS NOVOS ESTUDANTES
}

Bruno Henrique Romano - bhromano@gmail.com

Universidade Federal de Santa Catarina - Centro Tecnológico de Joinville

Rua Dona Francisca, 8300 - Bloco U

89219-600 - Joinville - Santa Catarina

Guilherme Cervi Garcia - guilhermecervigarcia@gmail.com

Universidade Federal de Santa Catarina - Centro Tecnológico de Joinville

Rua Dona Francisca, 8300 - Bloco U

89219-600 - Joinville - Santa Catarina

Carlos M. Sacchelli-carlos.sacchelli@gmail.com

Universidade Federal de Santa Catarina - Centro Tecnológico de Joinville

Rua Dona Francisca, 8300 - Bloco U

89219-600 - Joinville - Santa Catarina

Resumo: Ingressar em uma universidade é um desafio, mas, permanecer e aproveitar as oportunidades que a instituição oferece torna-se um desafio ainda maior. O Programa de Educação Tutorial (PET) - Engenharia da Mobilidade do campus de Joinville da Universidade Federal de Santa Catarina criou o projeto de acolhimento de ingressos chamado "Primeiros Passos". O projeto é composto de duas etapas: um tour com os estudantes pela instituição mostrando alguns laboratórios e uma apresentação com diversas entidades estudantis. Desta maneira este artigo tem como objetivo relatar as experiências obtidas pelo grupo PET EMB, as dificuldades e problemas enfrentados, e também como o projeto pode contribuir para a ambientação dos ingressantes, para reduzir a evasão e para a aproximação com o curso e com a universidade.

Palavras-chave: PET. Evasão. Acolhimento.

\section{INTRODUÇÃO}

O ingresso em uma universidade é uma nova etapa na vida de cada estudante, ao sair da escola de educação básica, passar no vestibular e iniciar a vida acadêmica alguns jovens se descobrem despreparados. Ao ingressar no Ensino Superior, em geral, entram em um universo com muita autonomia, no entanto, com escassos auxílios. Os jovens enfrentam mudanças de rotina, diferenças entre as exigências do ensino médio e do superior e muitas vezes passam a morar sozinhos. Este novo mundo de dificuldades, tanto em relação à vida cotidiana quanto em relação à vida na universidade, muitas vezes assusta e atrapalha os ingressantes (SALES et al, 2016). Situações estas que contribuem para elevar as taxas de evasão.

Por estas e outras razões, é visto que em todo o mundo, a taxa de evasão no primeiro ano de curso é normalmente de duas a três vezes maior do que a dos anos seguintes. Esse é um problema muito estudado e influencia na relação entre evasão anual e índice de titulação (SILVA FILHO, 2007). 
Como forma de contribuir para melhorar o ambiente estudantil e tentar reduzir a evasão são desenvolvidos projetos e programas nas instituições de ensino, dentre os projetos encontra-se o Programa de Educação Tutorial - PET. O PET foi criado em 1979 pela Coordenação de Aperfeiçoamento de Pessoal de Nível Superior e foi assumido pelo Ministério da Educação em 1999 (MARTINS, 2007).

De acordo com o MEC o objetivo do programa é melhorar o ambiente estudantil de uma instituição de ensino através dos três pilares da educação superior: ensino, pesquisa e extensão. Atualmente, o PET conta com 842 grupos espalhados pelo Brasil, sendo cada grupo formado por 12 bolsistas estudantes e 1 professor como tutor (MEC, 2020).

A Universidade Federal de Santa Catarina conta com 21 grupos PET, o campus na cidade de Joinville, conta com um grupo que é composto de estudantes dos 8 (oito) cursos, denominado de PET das Engenharias da Mobilidade (PET EMB).

O PET EMB propôs o projeto de acolhimento dos estudantes ingressantes no campus, denominado de "Primeiros Passos". O projeto visa introduzir os recém estudantes ingressantes, mostrando para os mesmos de como a instituição pode ajudá-los, os projetos de extensão, projetos de pesquisa e apresentar alguns laboratórios com ligação ao respectivo curso.

O campus da UFSC de Joinville oferta sete cursos de engenharia (Aeroespacial, Automotiva, Civil de Infraestrutura, Ferroviária e Metroviária, Mecatrônica, Naval, Transportes e Logística) e o bacharelado interdisciplinar em Ciência e Tecnologia.

Desta maneira este projeto tem como objetivo esclarecer as dúvidas dos estudantes sobre o campus e introduzi-los às possibilidades que são oferecidas por diversas entidades estudantis tendo como principal objetivo reduzir a evasão durante os primeiros anos da vida acadêmica dos alunos.

Este trabalho está organizado em três seções. Na primeira seção faz-se uma discussão sobre evasão, um dos problemas do Ensino Superior no Brasil. Na segunda seção apresenta-se o PET e o projeto "Primeiros Passos". Na terceira discute-se as dificuldades e as contribuições do projeto.

\section{EVASÃO NO ENSINO SUPERIOR}

Nos últimos anos no Brasil, cursos de engenharia tiveram crescimento na oferta e procura. Porém, algumas dificuldades no aprendizado podem levar o estudante a desistência no decorrer do curso. Este fenômeno é conhecido como evasão discente e é cada vez mais frequente nas instituições de ensino superior (ALVES, 2019).

A respeito do conceito de evasão, a Comissão Especial de Estudos sobre Evasão do MEC, o delimitou como sendo uma decisão ativa do estudante que decide desligar-se de seu curso superior atual por sua própria responsabilidade. Para fins de padronização, o mesmo documento assume que a evasão do Ensino Superior deve ser entendida em três níveis, quais sejam, evasão do curso, seja por abandono ou transferência; evasão da instituição, que implica a saída do estudante da instituição atual; e evasão do sistema, relativo ao abandono, temporário ou definitivo, do Ensino Superior (AMBIEL, 2015).

De acordo com dados do Sindicato das Mantenedoras de Ensino Superior entre os anos de 2012 e 2016, a taxa de evasão dos cursos presenciais no país teve um aumento, chegando em $30,1 \%$ na rede privada e $18,5 \%$ na rede pública. (Gráfico 1) 


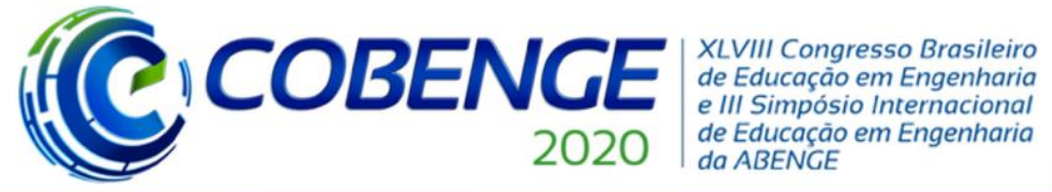

"Os desafios para formar hoje o engenheiro do amanhã"
01 a 03 de dezembro Evento On-line

Gráfico 1 - Taxa de evasão nas universidades entre 2012 e 2016

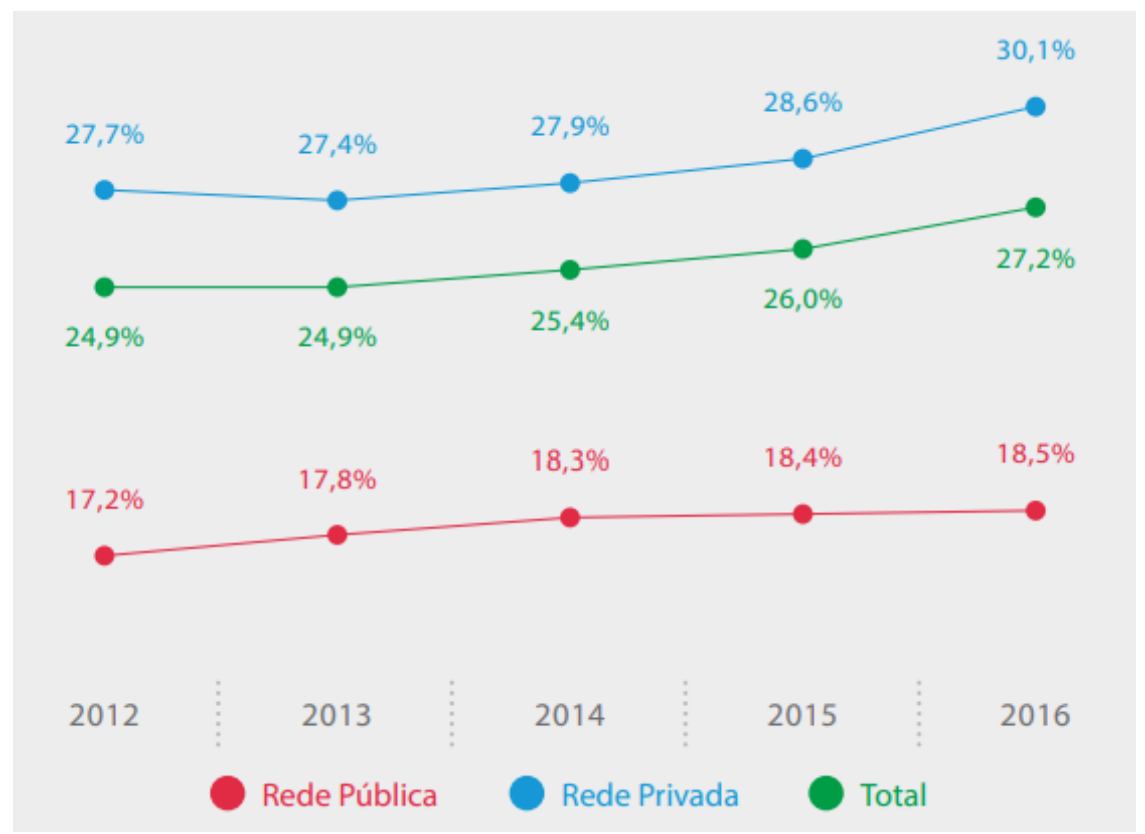

Fonte: Sindicato das Mantenedoras de ensino superior (2018).

Antes de sugerir estratégias de controle da evasão nas universidades faz-se necessário entender o que leva os estudantes a abandonarem as instituições. A partir de estudos e pesquisas realizados por Reis, Cunha e Spritzer (2012), as principais causas de evasão são:

- falta de tempo para o estudo pela necessidade de trabalhar;

- falta de identificação com a área que está cursando;

- não atendimento das expectativas dos estudantes por parte do curso;

- desmotivação para o estudo pelo emprego de práticas tradicionais de ensino

- dificuldades de aprendizado;

- desempenho ruim nas avaliações iniciais;

- bons salários em outras áreas de conhecimento e formação;

- dificuldade de adaptação à filosofia do Ensino Superior pelo costume com o Ensino Médio e a falta de subsídio ao estudante.

O Gráfico 2 demonstra dados sobre evasão conforme pesquisa desenvolvida. 
Gráfico 2 - Principais causas da evasão na engenharia

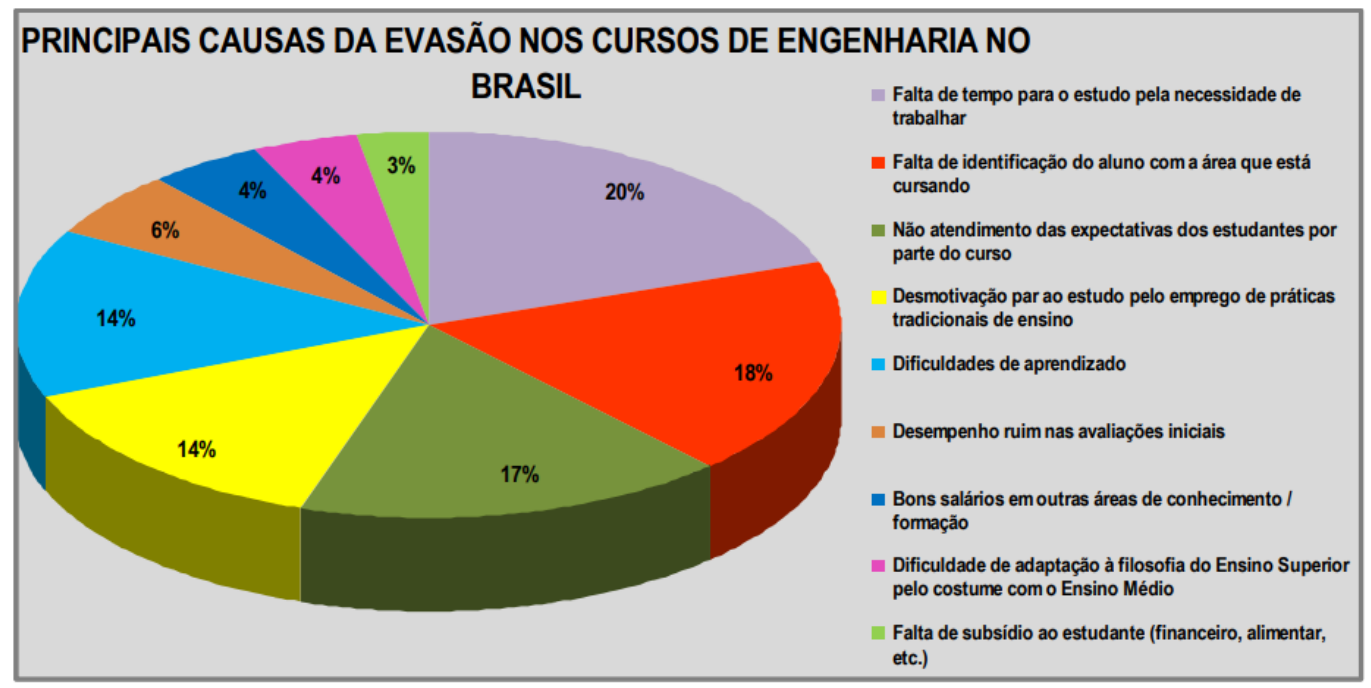

Fonte: Reis; Cunha e Spritzer (2012).

Tendo em vista a diminuição da taxa de evasão por parte dos discentes diversas ideias vêm sendo levantadas atualmente. Segundo Prestes e Rodrigues (2016) torna-se necessário oferecer diversificadas formas de aprendizagem, tanto dentro quanto fora da sala de aula. Uma forma de envolver e motivar os discentes é o desenvolvimento de atividades voltadas às práticas profissionais. Desse modo, as aulas práticas se destacam por permitir que o aluno tenha participação ativa, sendo construtor do próprio conhecimento, mostrando que a ciência e a tecnologia não são apenas aprendizados de fatos.

Outra proposta, sugerida por Falcão et al (2019), é desenvolver um programa que inclua um curso de nivelamento para as matérias técnicas base onde os calouros tenham uma revisão de conteúdos abordados no Ensino Médio e aulas introdutórias de conceitos iniciais. Além disso, o programa deve conter atividades com o propósito de inserir os estudantes no meio universitário, palestras sobre o curso e o mercado de trabalho, apresentação do corpo docente, assim como rodas de conversas com os veteranos.

De acordo com Reis, Cunha e Spritzer (2012) as estratégias de melhorias envolvem: a criação ou alteração do projeto pedagógico da instituição ou do curso; a reformulação curricular dos cursos; a integração do conhecimento, por meio da união de disciplinas, atividades práticas e extracurriculares; a mudança nas metodologias de ensino; o uso de novas tecnologias que promovam o ensino à distância, mas que ao mesmo tempo, intensifiquem a relação professor-estudante; a capacitação dos docentes a fim de prepará-los para o desenvolvimento de projetos inovadores, com a constante revisão de suas atividades; e a criação e manutenção de espaços físicos que auxiliem o processo de aprendizagem, tais como laboratórios, auditórios, bibliotecas, videotecas, etc.

Diante do exposto anteriormente, o PET EMB propôs o projeto "Primeiros Passos" para 
que os novos universitários se sintam acolhidos nos primeiros dias de aula, possibilitando também sair do ambiente de sala de aula para conhecer a estrutura da instituição como laboratórios, para que possam ter uma melhor identificação com a área de atuação do seu respectivo curso, possibilitando assim uma melhor adaptação com a filosofia do ensino superior.

\section{PROJETO PRIMEIROS PASSOS}

$\mathrm{Na}$ intenção de acolher e com o objetivo de contribuir para reduzir a evasão os membros do PET EMB perceberam a necessidade de mostrar aos ingressos um pouco mais da instituição, dessa forma desenvolveram, no segundo semestre de 2017, um projeto que visava introduzir os estudantes recém chegados aos principais laboratórios e espaços do campus da UFSC de Joinville.

Para alcançar este objetivo o grupo PET EMB a cada semestre escolhe um membro para ser responsável pelo projeto e mais quatro para ajudá-lo na organização. Após a seleção da equipe o responsável entra em contato com professores para disponibilizarem uma aula em função dos tours. Em seguida distribui as atividades para o grupo, sendo estas o planejamento das 8 visitas guiadas e o da apresentação das entidades. O planejamento é realizado em planilhas, nelas constam os espaços, os horários e os responsáveis. Planilhas as quais todo grupo tem acesso.

Finalizada a parte de organização todos os membros do PET EMB participam da parte prática, visando não sobrecarregar ninguém uma vez que o projeto é executado em uma única semana. Na execução todos seguem o cronograma definido nas planilhas.

$\mathrm{Na}$ visita guiada, são visitadas algumas partes do campus como secretaria e assistência estudantil, mostrado alguns locais importantes como o restaurante universitário, cantina e biblioteca, e também, são visitados alguns laboratórios (Figura 1). A parte técnica das visitas guiadas é planejada individualmente em relação aos cursos, portanto os laboratórios variam conforme a área da engenharia.

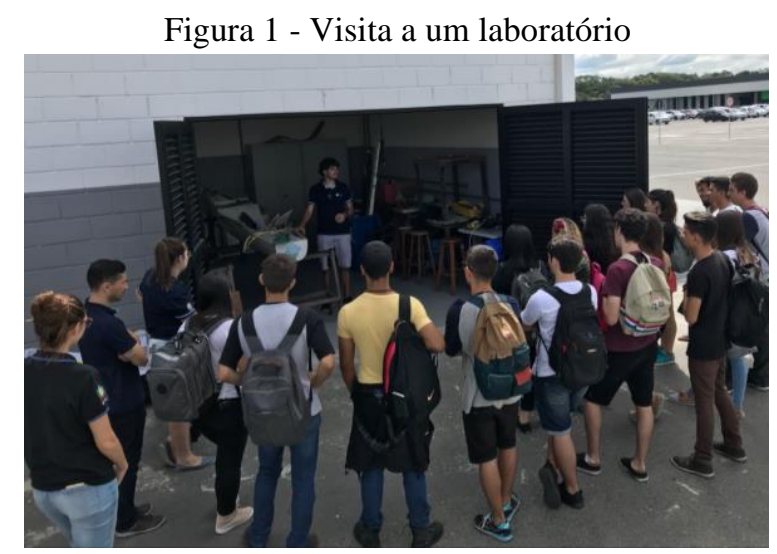

Fonte: os Autores (2020).

A apresentação com as entidades estudantis do campus (Figura 2) é realizada com o intuito de mostrar aos estudantes algumas das atividades extracurriculares que podem ser 
realizadas, como equipes de competições, centros acadêmicos, empresas juniores, PETs entre outras atividades. Normalmente, entre 15 e 20 entidades se apresentam tendo de 4 a 5 minutos para divulgar e explicar brevemente qual seu papel na universidade e os seus resultados na formação do estudante. A visita guiada e a apresentação das entidades têm a mesma duração em torno de duas horas aula.

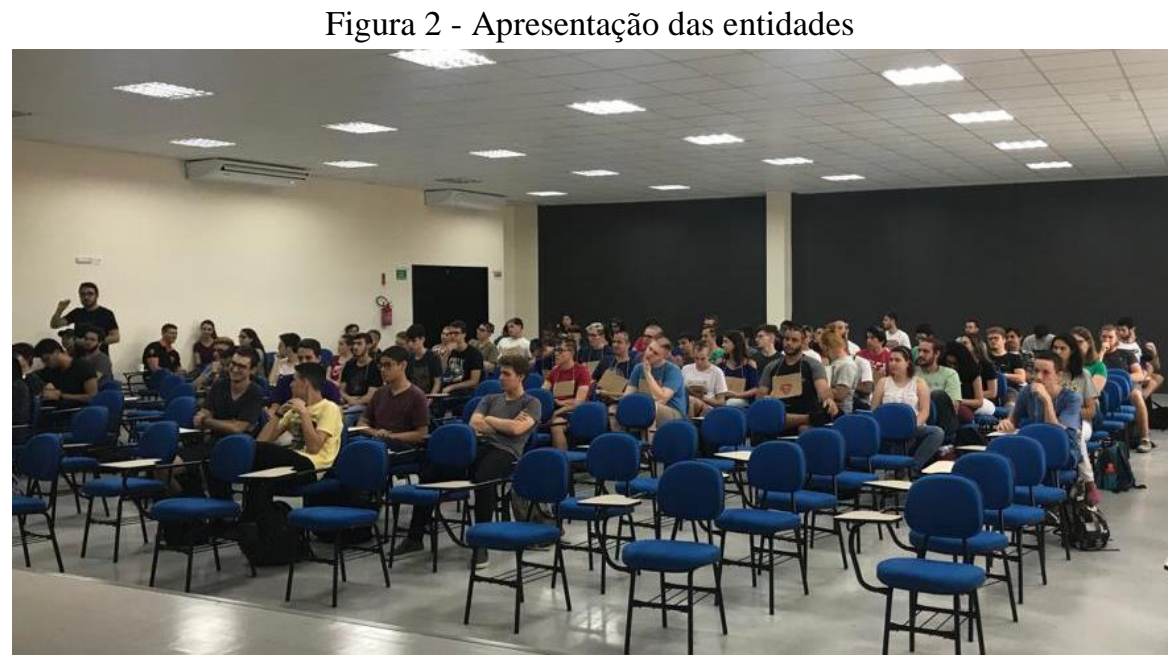

Fonte: os Autores (2020).

Como forma de fazer uma avaliação do projeto em relação à qualidade da atividade são enviados dois formulários para cada estudante, um sobre o tour e outro sobre a apresentação. Neste são realizadas perguntas em relação a qualidade da visita em cada laboratório, se a iniciativa contribuiu para um melhor entendimento do seu curso de graduação e se o PET EMB atendeu e respondeu as dúvidas dos estudantes.

Com o objetivo de melhorar o projeto para as próximas edições foi feito análise mais minuciosa em relação às visitas aos laboratórios, foi pedido que avaliassem cada laboratório com uma nota entre 1 e 5 .

\section{RESULTADOS E DISCUSSÕES}

Após cinco edições do projeto e aproximadamente 800 estudantes que participaram foi possível coletar informações em relação à qualidade da execução e em relação ao impacto causado pelo projeto "Primeiros Passos" nos ingressos.

A partir dos formulários de feedback das visitas guiadas, foram obtidos que após estes, todos os estudantes adquiriram uma maior compreensão acerca do próprio curso e de sua abrangência, outro resultado foi que $94.3 \%$ dos estudantes consideraram os membros do PET atenciosos durante a execução. Já em relação aos formulários da apresentação das entidades todos os que responderam consideraram os membros atenciosos e $98 \%$ avaliou que a apresentação ajudou a entender o próprio curso, obtivemos também comentários elogiando a apresentação e criticando a falta de tempo para cada entidade se apresentar.

Ao decorrer destas edições, foram encontradas algumas dificuldades em relação a sua realização. Entre elas destacam-se: a dificuldade de comunicação com alguns professores, 
sendo ela feita principalmente por e-mail, o que fez com que os organizadores do projeto entrassem em contato com os professores 1 ou 2 meses antes da execução do projeto; laboratórios fechados durante as visitas guiadas, o que leva a uma ação de maior comunicação com o responsável de cada laboratório.

Há também a falta de tempo na apresentação de cada entidade, esse é um problema cuja solução se torna mais complexa, uma vez que algumas equipes extrapolam o tempo de apresentação o que compromete a organização do projeto, porém algumas estratégias foram adotadas e com isso foi possível amenizar este problema. Como informar o tempo antecipadamente para cada equipe para que elas consigam se preparar melhor, marcar o tempo de cada apresentação e mostrar algumas entidades durante os tours, dando oportunidade para que consigam passar mais informações.

Com o intuito de uma melhor análise dos dados dos formulários foi feito uma média das notas dadas por cada um dos estudantes no tour em geral. Por fim a nota obtida na avaliação dos tours de todos os estudantes teve uma média de 4.54 de um total de 5 , o que reforça que o projeto é bom aproveitado pelos estudantes ingressantes na instituição.

\section{CONCLUSÃO}

A partir das respostas recebidas nos formulários é possível perceber o impacto positivo que o projeto de acolhimento "Primeiros Passos" gera nos ingressos, ajudando-os a compreender melhor o novo ambiente e curso no qual estão entrando.

Os laboratórios e as entidades têm interesse em se apresentar pela possibilidade de promover seus projetos e por consequência, conseguir novos integrantes.

Apesar de certas dificuldades é viável a realização em outras instituiçõos, independente do curso de ingresso do estudante, para colaborar com a introdução do aluno ao meio acadêmico.

Corroborando com os objetivos do projeto "Primeiros Passos" os autores Ambiel, Santos e Dalbosco (2016) em pesquisas realizadas com 153 estudantes de uma universidade particular concluíram que o investimento das instituições de ensino superior na manutenção dos estudantes nos cursos passa por providenciar boas condições de relacionamento e bemestar geral, além da disponibilização de possibilidades para o desenvolvimento de habilidades para lidar com as decisões de carreira.

Acredita-se que o projeto ao apresentar a Universidade para além das salas de aula aproxima os estudantes de colegas de curso bem como do curso. Práticas dessa natureza contribuem para reduzir a evasão discente.

\section{Agradecimentos}

Os autores agradecem o Ministério da Educação e ao FNDE pela oportunidade de bolsa dentro do Programa de Educação Tutorial das Engenharias da Mobilidade (PET EMB). À universidade pelo apoio ao programa e apoio ao nosso projeto. Ao nosso tutor pelo suporte em todo projeto, e o suporte e trabalho conjunto dos colegas de equipe.

\section{REFERÊNCIAS}

ALVES, Rafaelly Beserra; COSTA, Heloina Nogueira. Abordagem prática no ensino de 
"Os desafios para formar hoje o engenheiro do amanhã"

materiais de construção para engenharia. In: COBENGE, 2019, Fortaleza. Anais: Fortaleza, 2019.

AMBIEL, Rodolfo A. M. Construção da Escala de Motivos para Evasão do Ensino Superior. Avaliação Psicológica, 14(1), pp. 41-52, 2015.

MARTINS, Iguatemy L. Educação Tutorial no ensino presencial: uma análise sobre o PET. PET-Programa de Educação Tutorial: estratégia para o desenvolvimento da graduação. Brasília: Ministério da Educação, 2007.

MEC. Apresentação PET. Disponível em: <http://portal.mec.gov.br/pet/pet>. Acesso em 22 abr. de 2020.

REIS,Vivian Wildhagen; CUNHA, Paulo José Monteiro da; SPRITZER, Ilda Maria da Paiva Almeida. Evasão no Ensino Superior de Engenharia no Brasil: Um Estudo de Caso no CEFET/RJ. COBENGE 2012, Belém. Anais: Belém, 2012

SALES, Diogo S. de S.; MACHADO, Nayara R. de S.; GONÇALVES, Patrícia G.;

NOGUEIRA, Francielle C.; PERREIRA, Carlos A. Orientação Acadêmica da Engenharia de Minas da Universidade Federal de Ouro Preto. In: XLIV Congresso Brasileiro de Educação em Engenharia, 2016, Natal. Anais: Natal, 2016.

SILVA FILHO, Roberto Leal Lobo et al. A evasão no ensino superior brasileiro. Cadernos de pesquisa, v. 37, n. 132, p. 641-659, 2007.

SINDICATO DAS MANTENEDORAS DE ENSINO SUPERIOR. Mapa do Ensino Superior no Brasil. 8a Edição, 2018, Disponível em: https://www.semesp.org.br/>. Acesso em: 17 de maio de 2020.

\section{FIRSTS STEPS PROJECT: RECEPTION ALTERNATIVE TO NEW STUDENTS}

Abstract: Joining a university is a challenge, but maintaining and taking advantage of the opportunities the institution offers becomes an even greater challenge. The Tutorial Education Program (PET) - Mobility Engineering at the Joinville campus of the Federal University of Santa Catarina created the ticket reception project called "First Steps". The project consists of two stages: a tour with students through the institution that shows some laboratories and a presentation with several student entities. In this way, this article aims to relate how to experience the PET EMB group, how difficulties and problems faced, and also how the project can contribute to the setting of new students, to reduce dropout and to get closer to the course and the university.

Keywords: PET. Evasion. Reception. 